support from hospice educators, including a forum for peer support and ongoing relationships.

Conclusion The project will equip care home staff to facilitate in-house end-of-life education and training to maintain a standard of care that meets the recommendations as highlighted in the Ambitions document (National Palliative and End of Life Care Partnership, 2021) . This project will maintain ongoing engagement with care homes through a relationship of mutual professional trust and respect, facilitating peer support within the care home community, and at the same time recognising the specific challenges that care homes face.

\section{P-196 CREATING A SUPPORTIVE KNOWLEDGE NETWORK THROUGH THE PANDEMIC FOR WORCESTERSHIRE'S CARE HOMES VIA THE ECHO PLATFORM}

Donna Jones, Lucy Gallagher. St Richard's Hospice, Worcester, Worcestershire

\subsection{6/spcare-2021-Hospice.212}

Background In 2018 our hospice became an 'Extension for Community Health Outcomes', (ECHO) Hub. In March 2020 we were approached by the Care Home GP Lead from the CCG. She had quickly identified that the care homes across the county were struggling in light of the pandemic and a platform to provide information, guidance and support was required. As host to an ECHO Hub, we were well placed to support this call to action.

Aim 'Project ECHO provides a way where hospitals doing fantastic stuff can also help communities to do fantastic stuff, while learning about what they need to do together.' Prof Max Watson (Eaton, 2019).

With these words in mind, the ethos of pulling a community together and sharing information in a time of need was foremost in our minds. Utilising the ECHO Platform would allow us to reach care homes across the whole county.

Method A weekly meeting commenced in April 2020, reaching participant numbers of 50 plus on a regular basis. The GP Lead led the meetings with guest speakers from the CCG Infection Control team, County Council and Public Health England. Subjects such as guidance on care home visiting were high on the agenda.

Results April 2020 - to August 2020, 790 participants attended the weekly meetings. We then moved on to create a more traditional palliative care knowledge network programme for the homes and have delivered five cohorts to date - consisting in total of 351 attendees. We were also able to deliver Verification of Expected Death training via the ECHO platform. 1,259 care home staff reached since the start of the pandemic.

Conclusions As a result of this work it has been possible to support the homes and to work better together. This displays the ECHO ethos at its best as a project.

\section{P-197 CARE HOME VIRTUAL OPEN-ACCESS INTEGRATED CLINIC AND ECHO SUPPORT: ST LUKE'S COVID-19 RESPONSE}

Emma Westerdale-Shaw, Lynne Ghasemi, Jane Manson, Helen Cawley. St Luke's Hospice, Sheffield, UK

10.1136/spcare-2021-Hospice.213
Background Early in the COVID-19 pandemic, care homes felt inadequately valued and considered by policy makers with centrally organised governmental response having counterproductive effects (Marshall, Gordon, Gladman, et al., 2021). Care home staff felt increasingly isolated, with a fifth of social care staff considering leaving the profession (Gordon, Goodman, Achterberg, et al., 2020). A swift response was developed by St Luke's Hospice to support care homes in Sheffield, not only with palliative care, but also with information dissemination and peer support between care homes.

Aims

- Provide alternative face-to-face assessment in care homes enabling remote end-of-life.

- Support appropriate admission avoidance.

- Enable clinical skills development, increased confidence and competence, and psychological support in care homes during the COVID-19 pandemic.

Methods The Care Homes VOICES project supported care homes by providing the following services:

- Care home managers' weekly virtual forum based on ECHO principles for care home managers. Guest speakers included infection control experts, public health, and local commissioners.

- Care home education programme - based on ECHO principles included: symptom identification, PPE donning/ doffing, managing recovery, and later vaccine advice.

- Clinical skills training - multifaceted syringe driver training and competencies.

- Specialist palliative care team input - initially virtually and later face-to-face.

- Dedicated care home memorials and bereavement care.

Results Number of specialists/experts attending: 105. Average attendance at managers' forum: 35. Number of CHs attending ECHO sessions: 47. Number of new care homes joined ECHO: 17. Number of individuals syringe driver trained: 39. Approximately 100 individuals attended a hospice-led remembrance. Qualitative responses suggest care homes benefitted from support received:

We are dealing with lots of deaths... discussion is needed and the opportunity to reflect and think about my practice.'

'The COVID-19 programme has been so important for our staff - they have been able to understand and talk about changes to guidance and their own experiences.'

Conclusions The VOICES project has demonstrated how multi-faceted interventions can educate care home staff, disseminate resources, and provide psychological and clinical support amid a pandemic.

\section{P-198 CARE HOME STAFF EXPERIENCES OF PALLIATIVE AND END-OF-LIFE CARE IN CARE HOMES DURING COVID-19}

${ }^{1}$ Izabele Batkovskyte, 'Lori Bourke, ${ }^{1}$ Clare Ellis-Smith, ${ }^{1}$ Anna Bone, ${ }^{2}$ Claire Goodman, ${ }^{3}$ Stephen Barclay, ${ }^{1}$ Irene Higginson, ${ }^{1}$ India Tunnard, ${ }^{4}$ Margaret Ogden, ${ }^{1}$ Catherine Evans, ${ }^{1}$ Katherine Sleeman. ${ }^{1}$ King's College London, London, UK; ${ }^{2}$ University of Hertfordshire, Hatfield, UK; ${ }^{3}$ University of Cambridge, Cambridge, UK; ${ }^{4} \mathrm{PPI}$, London, UK

\subsection{6/spcare-2021-Hospice.214}

Background COVID-19 has had a devastating impact on care homes, their residents and staff. Over 37,000 UK care home residents have died from COVID-19; many more have 